\title{
Sodium glucose cotransporter 1 ligand BLF501 as a novel tool for management of gastrointestinal mucositis
}

Diego Cardani ${ }^{1}$, Claudia Sardi ${ }^{1,2}$, Barbara La Ferla ${ }^{3}$, Giuseppe D'Orazio ${ }^{3}$, Michele Sommariva ${ }^{4,5}$, Fabrizio Marcucci ${ }^{6}$, Daniela Olivero ${ }^{7}$, Elda Tagliabue ${ }^{5}$, Hermann Koepsell ${ }^{8}$, Francesco Nicotra ${ }^{3}$, Andrea Balsari ${ }^{4,5}$ and Cristiano Rumio ${ }^{1,2^{*}}$

\begin{abstract}
Background: Recent studies demonstrated that engagement of sodium glucose transporter 1 (SGLT-1) by orally administered D-glucose protects the intestinal mucosa from lipopolysaccharide (LPS)-induced injury. We tested whether SGLT-1 engagement might protect the intestinal mucosa from doxorubicin (DXR)- and 5-fluorouracil (5-FU)-induced injury in animal models mimicking acute or chronic mucositis.
\end{abstract}

Methods: Mice were treated intraperitoneally with DXR, alone or in combination with 5-FU, and orally with BLF501, a glucose-derived synthetic compound with high affinity for SGLT-1. Intestinal mucosal epithelium integrity was assessed by histological analysis, cellular proliferation assays, real-time PCR gene expression assays and Western blot assays. Student's t-test (paired two-tailed) and $x^{2}$ analyses were used for comparisons between groups. Differences were considered significant at $\mathrm{p}<0.05$.

Results: BLF501 administration in mice treated with DXR and/or 5-FU decreased the injuries to the mucosa in terms of epithelial integrity and cellular proliferative ability. Co-treatment with BLF501 led to a normal expression and distribution of both zonula occludens-1 (ZO-1) and beta-catenin, which were underexpressed after treatment with either chemotherapeutic agent alone. BLF501 administration also restored normal expression of caspase-3 and ezrin/radixin/moesin (ERM), which were overexpressed after treatment with DXR and 5-FU. In SGLT1-/- mice, BLF501 had no detectable effects. BLF501 administration in wild-type mice with growing A431 tumors did not modify antitumor activity of DXR.

Conclusions: BLF501-induced protection of the intestinal mucosa is a promising novel therapeutic approach to reducing the severity of chemotherapy-induced mucositis.

Keywords: Gastrointestinal mucositis, SGLT-1, Synthetic D-glucose analogs, Chemotherapy, Inflammation

\section{Introduction}

Oral and gastrointestinal mucositis are serious side effects of chemotherapy. Severe mucositis is especially common among patients who receive aggressive myeloablative chemotherapy and in patients who receive therapy for head and neck cancer [1-3]. Mucositis is a complex, multifactorial process which affects all layers of the gastrointestinal tract $[4,5]$ and is characterized by apoptosis and

\footnotetext{
* Correspondence: cristiano.rumio@unimi.it

'Department of Pharmacology and Biomolecular Sciences, Università degli

Studi di Milano, Via Trentacoste 2, 20133 Milan, Italy

${ }^{2}$ Humanitas Clinical and Research Center, Via Manzoni 56, 20089 Rozzano, Milan, Italy

Full list of author information is available at the end of the article
}

reduced proliferation of epithelial cells in the intestinal crypts, villus atrophy and collagen breakdown. Mucositis impedes the efficacy of treatment protocols because it may require chemotherapy interruption, reduction in drug dosages or change to other antitumor drugs [6-8]. Treatment of mucositis is mainly symptomatic. In recent years, Palifermin has been successfully adopted for treatment of oral mucositis during chemotherapy of hematologic cancers [9]. However, except for "guidelines" for symptom management, no well-established therapeutic strategies to treat chemotherapy-induced intestinal mucositis are available [10-12]. Thus the development of an effective

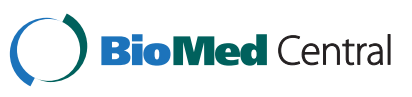


intervention against chemotherapy-related mucositis has high priority in oncological supportive care $[13,14]$.

The sodium-glucose cotransporter 1 (SGLT-1) is a highcapacity glucose transporter expressed mainly in the apical membrane of epithelial cells lining the S3 segment of the proximal renal tubule and the intestinal epithelium $[15,16]$. SGLT-1 is the most important transporter of D-glucose and D-galactose from the small intestinal lumen into enterocytes and is upregulated in response to glucose in food [17]. Recent reports suggest additional roles for SGLT-1 which may not be directly linked to transport. For example, expression of SGLT-1 was shown to be necessary to preserve the integrity of plasma membranes and tight junctions in tubular renal epithelial cells after exposure to cisplatin in vitro $[16,18]$. Moreover, we have shown in a mouse model of septic shock that oral administration of high doses of D-glucose or the non-metabolized glucose analog 3-0-methyl-D-glucopyransoide protected the intestinal epithelium from lipopolysaccharide-induced inflammatory injury $[19,20]$. Based on these data, we speculated that SGLT-1-mediated signaling might be beneficial in maintaining intestinal mucosal integrity from chemotherapy-induced damage. To test this hypothesis, we examined the effects of BLF501 (formerly called "compound 5"), a synthetic compound which binds to SGLT-1 withdrawal [21], in a mouse model of doxorubicin (DXR)and 5-fluorouracil (5-FU)-induced intestinal injury. Here, we show that BLF501-induced SGLT-1 activation protects against DXR- and 5-FU-induced injury by promoting proliferation of enterocytes and correct formation of tight and adherens junctions. BLF501 does not appear to interfere with drug antitumor activity.

\section{Results}

Oral administration of BLF501 protects against alterations of the small intestine induced by a single administration of DXR

The effect of BLF501 on alterations of the small intestine induced by DXR was evaluated in mice treated with: DXR alone $(20 \mathrm{mg} / \mathrm{kg}$ i.p., $\mathrm{n}=14)$; DXR plus BLF501 $(25 \mu \mathrm{g} / \mathrm{kg}$ BLF501, $\mathrm{n}=14)$; BLF501 alone $(\mathrm{n}=14)$; or left untreated $(n=7)$. Half of the mice were sacrificed after $48 \mathrm{~h}$ and the other half, after $72 \mathrm{~h}$ (Table 1). The same evaluations was performed on SGLT-1 ${ }^{-1-}$ mice after $72 \mathrm{~h}$ of treatment with DXR with or without BLF501 co-treatment (Table 1).

Macroscopic examination of small intestine samples collected at 48 or $72 \mathrm{~h}$ revealed only early-stage morphological alterations, whereas immunofluorescence BrdU assay revealed a significantly reduced proliferation rate of crypt cells in DXR-treated mice [DXR $1.3 \pm 0.2 \%$ at $48 \mathrm{~h}$; $0.8 \pm 0.6 \%$ at $72 \mathrm{~h}$, UNTR $2.3 \pm 2.2 \%$ at $72 \mathrm{~h}$; UNTR $v s$ DXR, $p=0.0086(48 \mathrm{~h})$ and $\mathrm{p}=0.023(72 \mathrm{~h})]$ that was absent in mice treated simultaneously with DXR and BLF501 [DXR + BLF501 $3.3 \pm 0.5 \%$ and $2.2 \pm 0.5 \%$ at 48 and $72 \mathrm{~h}$, respectively; DXR + BLF501 vs DXR $\mathrm{p}=0.004(48 \mathrm{~h})$ and $\mathrm{p}=0.028$ (72 h)] (Figure 1). In SGLT1-/- mice, proliferation was dramatically increased compared to that in wild-type mice, but no modification of intestinal epithelial cell proliferation was observed in samples from mice treated with BLF501 alone. BLF501 proved to be inactive in SGLT-1 ${ }^{-/-}$ mice, with no improvements in cellular proliferation rate observed at $72 \mathrm{~h}$ after DXR treatment in combination with BLF501 (mean \pm SD, UNTR, $11.09 \pm 1.93 \%$; DXR, $7.38 \pm$ 2.71\%; DXR + BLF501, $8.24 \pm 4.59 \%$. UNTR vs DXR, $\mathrm{p}=$ 0.0012; DXR vs DXR + BLF501, $\mathrm{p}=0.3870$ ).

Expression of beta-catenin, a unique intracellular protein functioning as an integral component of the cell-cell adhesion complex and as a principal signaling protein in the canonical Wnt pathway linked to cell proliferation [22,23], was reduced at $48 \mathrm{~h}$ after DXR administration in the villi and, at $72 \mathrm{~h}$, in both villi and crypts of wild-type mice. Treatment with BLF501 was found to maintain the physiological expression of beta-catenin (Figure 2).

Further analysis of the protective effect of BLF501 focused on the expression of different genes implicated in the early response to tissue injury [24], including: DLL-1, a marker of crypt cells actively proliferating in a stem celllike manner [25]; TFF-3 and beta-actin, components of the mucus layer [26] and the cytoskeleton, respectively, and whose reduced expression mirrors decreased mucin production and alteration of cytoskeletal structure, respectively; and sucrose isomaltase, a marker for brush border integrity [24] and a key enzyme in carbohydrate metabolism, whose reduced expression mirrors epithelial damage and nutrient malabsorption [27]. Expression of all of these markers was reduced at $48 \mathrm{~h}$ after DXR treatment, but, after co-treatment with BLF501, was similar to that in control mice (Figure 3).

\section{BLF501 protects the small intestine mucosa from injury induced by repeated administration of DXR and 5-FU}

We also evaluated the effect of BLF501 in a mouse model of DXR- and 5-FU-induced mucositis. The addition of 5-FU is necessary to stabilize and standardize DXR action, reducing the variability of epithelial damages in this model mimicking medium-term chemotherapy-induced effects on the intestinal mucosa, in particular, morphology and cellular population alterations and junctional systems integrity [24,28-30]. Intestinal epithelium from mice treated with the two chemotherapeutics was extensively damaged (Figure 4A-F). In particular, villi were atrophic, fused and reduced in height $(-36.15 \pm 2.56 \%$ vs untreated); epithelial cells were hyperplastic and brush borders had large areas of erosion; focal ectasia of chyliferous vessels was detectable; numbers of goblet cells were decreased (DXR + 5-FU $2.56 \pm 1.28 \%$ vs untreated $7.13 \pm 0.64 \%, \mathrm{P}=0.0065)$; and cells undergoing mitosis and cellular infiltrates rich in 
Table 1 Summary of in vivo treatments

\begin{tabular}{|c|c|c|c|c|c|c|c|c|}
\hline \multicolumn{9}{|c|}{ I. BLF501 action/single DXR injection } \\
\hline Mouse strain & Group & Mice/Group & DXR & $\begin{array}{l}\text { BLF501 } \\
25 \mu \mathrm{gg} / \mathrm{kg}\end{array}$ & Sacrifice $48 \mathrm{~h}$ & Sacrifice $72 \mathrm{~h}$ & \multicolumn{2}{|c|}{ BrdU injection } \\
\hline \multirow[t]{4}{*}{$\mathrm{BALB} / \mathrm{C}$} & UNTR & $N=7$ & - & - & - & $N=7$ & \multicolumn{2}{|l|}{+} \\
\hline & DXR & $N=14(7+7)$ & + & - & $N=7$ & $N=7$ & \multicolumn{2}{|l|}{+} \\
\hline & $\begin{array}{l}\text { DXR +BLF501 } \\
25 \mu \mathrm{g} / \mathrm{kg}\end{array}$ & $N=14(7+7)$ & + & + & $N=7$ & $N=7$ & \multicolumn{2}{|l|}{+} \\
\hline & $\begin{array}{l}\text { BLF501 } \\
25 \mu \mathrm{g} / \mathrm{kg}\end{array}$ & $N=14(7+7)$ & - & + & $N=7$ & $N=7$ & \multicolumn{2}{|l|}{+} \\
\hline Mouse strain & Group & Mice/Group & DXR & $\begin{array}{l}\text { BLF501 } \\
25 \mu \mathrm{gg} / \mathrm{kg}\end{array}$ & Sacrifice $48 \mathrm{~h}$ & Sacrifice $72 \mathrm{~h}$ & \multicolumn{2}{|c|}{ BrdU injection } \\
\hline \multirow[t]{3}{*}{ C57 SGLT-1 -/- } & UNTR & $N=7$ & - & - & - & $N=7$ & \multicolumn{2}{|l|}{+} \\
\hline & DXR & $N=7$ & + & - & - & $N=7$ & \multicolumn{2}{|l|}{+} \\
\hline & $\begin{array}{l}\text { DXR +BLF501 } \\
25 \mu \mathrm{g} / \mathrm{kg}\end{array}$ & $N=7$ & + & + & - & $N=7$ & \multicolumn{2}{|l|}{+} \\
\hline \multicolumn{9}{|c|}{ II. BLF501 action/repeated DXR plus 5-FU injections } \\
\hline Mouse strain & Group & Mice/Group & $\mathrm{DXR}+5-\mathrm{FU}$ & $\begin{array}{c}\text { BLF501 } \\
0.25 \mu \mathrm{g} / \mathrm{kg}\end{array}$ & BLF501 $2.5 \mu \mathrm{g} / \mathrm{kg}$ & $\begin{array}{l}\text { BLF501 } \\
25 \mu \mathrm{gg} / \mathrm{kg}\end{array}$ & Treatment days & Sacrifice day \\
\hline \multirow[t]{6}{*}{$\mathrm{BALB} / \mathrm{C}$} & UNTR & $N=7$ & - & - & & & - & \\
\hline & $\mathrm{DXR}+5 \mathrm{FU}$ & $N=7$ & + & - & & & \multirow{2}{*}{\multicolumn{2}{|c|}{ Days 1,8 and 15}} \\
\hline & $\begin{array}{l}\text { DXR + 5FU +BLF501 } \\
0.25 \mu \mathrm{g} / \mathrm{kg}\end{array}$ & $N=7$ & + & + & & & & \\
\hline & $\begin{array}{l}\text { DXR + 5FU +BLF501 } \\
2.5 \mu \mathrm{g} / \mathrm{kg}\end{array}$ & $N=7$ & + & - & + & & & Day 19 \\
\hline & $\begin{array}{l}\text { DXR + 5FU +BLF501 } \\
25 \mu \mathrm{g} / \mathrm{kg}\end{array}$ & $N=7$ & + & - & - & + & & \\
\hline & BLF501 $25 \mu \mathrm{g} / \mathrm{kg}$ & $N=7$ & - & - & - & + & & \\
\hline \multicolumn{9}{|c|}{ III. BLF501/DXR interaction } \\
\hline Mouse strain & Group & Mice/Group & DXR & $\begin{array}{l}\text { BLF501 } \\
25 \mu \mathrm{g} / \mathrm{kg}\end{array}$ & Treatment days & \multicolumn{3}{|c|}{ Sacrifice day } \\
\hline \multirow[t]{4}{*}{ SKH-1 } & UNTR & $N=8$ & - & - & - & \multicolumn{3}{|c|}{ Day 26} \\
\hline & DXR & $N=8$ & + & - & \multirow{3}{*}{$\begin{array}{l}\text { Days } 7,14 \text { and } 21 \\
\text { after cell injection }\end{array}$} & & & \\
\hline & $\begin{array}{l}\text { DXR +BLF501 } \\
25 \mu \mathrm{g} / \mathrm{kg}\end{array}$ & $N=8$ & + & + & & & & \\
\hline & BLF501 & $N=8$ & - & + & & & & \\
\hline
\end{tabular}

lymphocytes and plasma cells were observed. Mice treated with $25 \mu \mathrm{g} / \mathrm{kg}$ BLF501 showed substantial recovery from chemotherapy-induced injury to the intestinal mucosa (villus height: $-12.31 \pm 1.58 \%, \mathrm{p}=0.0014$ vs untreated; goblet cells: $6.93 \pm 0.63 \%, \mathrm{p}=0.0383$ vs untreated). At $2.5 \mu \mathrm{g} / \mathrm{kg}$, BLF501 improved morphological parameters (villus height: $-16.82 \pm 1.33 \%, \mathrm{p}=0.0026$ vs untreated), but was ineffective against loss of goblet cells $(2.2 \pm 1.72 \%)$ and appearance of mitotic cells; at $0.25 \mu \mathrm{g} / \mathrm{kg}$, BLF501 had no effect on any of the parameters examined. Samples from the intestinal epithelia of mice treated with BLF501 alone were identical to those of control mice. Figure $4 \mathrm{G}$ summarizes these results.

To examine the junctional systems of the intestinal epithelia of mice treated with the chemotherapeutics alone or together with BLF501, we focused on the expression of ZO-1, which mirrors the integrity of tight junctions [31,32], and beta-catenin, a component of adherens junctions [33]. Immunofluorescence and immunohistochemical staining of junctional systems revealed decreased expression of ZO-1 and an altered distribution of beta-catenin, respectively, in intestinal samples from DXR/5-FU-treated mice, whereas samples from mice that also received BLF501 at $25 \mu \mathrm{g} / \mathrm{kg}$ showed the typical honeycomb distribution of ZO-1 and expression/distribution of beta-catenin similar to that in control mice; the $2.5 \mu \mathrm{g} / \mathrm{kg}$ BLF501 dose was less effective. BLF501 $(25 \mu \mathrm{g} / \mathrm{kg})$ alone did not alter the expression or distribution of either ZO-1 or beta-catenin (Figure 5A-J).

We then evaluated extracts of small intestine samples for the expression of ERM proteins, which play a crucial 

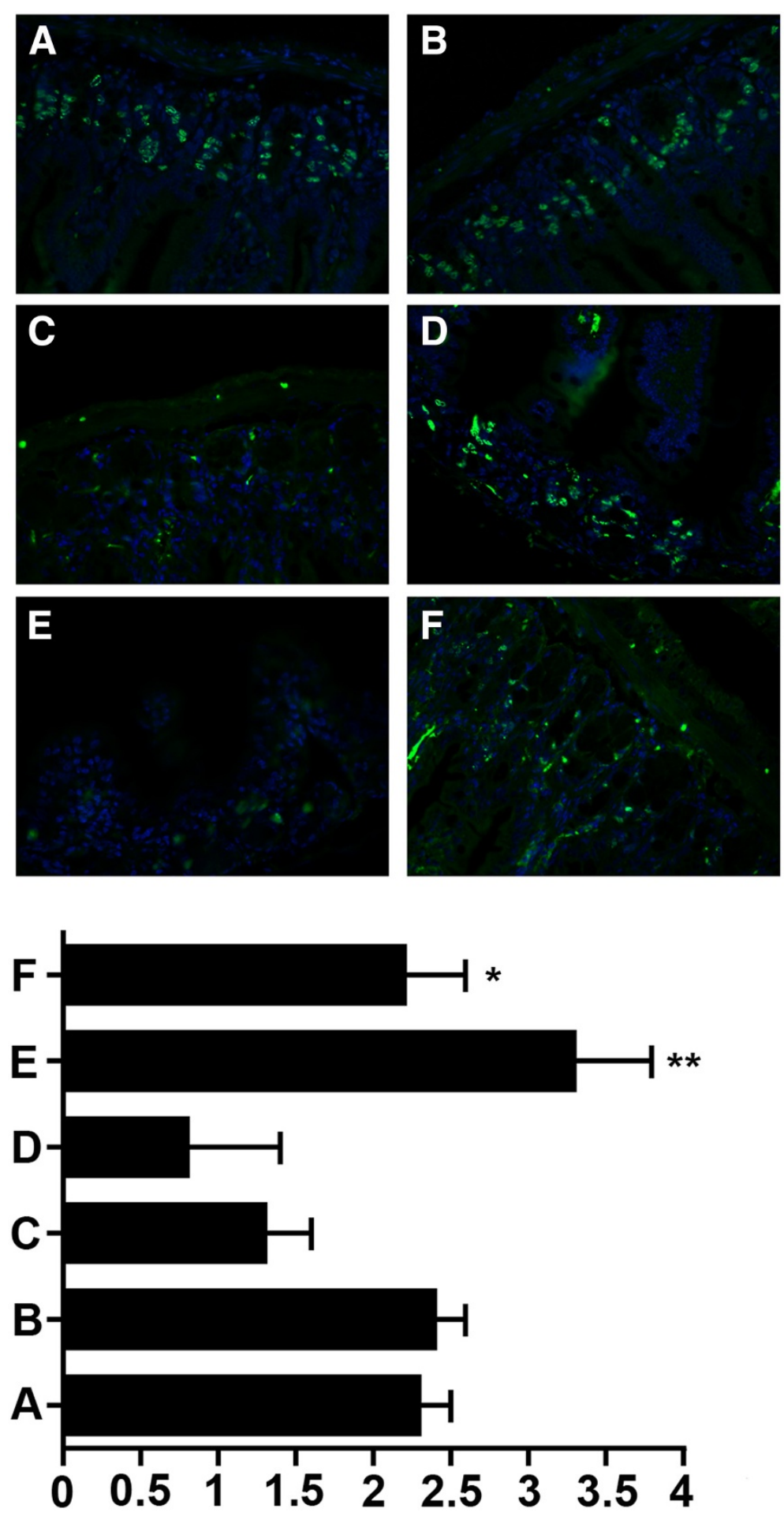

\section{PERCENTAGE OF PROLIFERATING CELLS}

Figure 1 Preservation of cell proliferation by BLF501 in small intestinal crypts of mice treated with a single administration of DXR. Immunofluorescence assay for BrdU-positive proliferating cells was performed. DXR-induced decrease of proliferation rate apoptosis was observed at the three- to six-cell positions within crypts. Positive cells count was performed. (A) UNTR, untreated; (B) BLF501 25 Hg/kg; (C) DXR 48 h; (D) DXR 72 h; (E) DXR + BLF501 $25 \mu \mathrm{g} / \mathrm{kg} 48$ h; (F) DXR + BLF501 $25 \mu \mathrm{g} / \mathrm{kg} 72 \mathrm{~h}$. DXR + BLF501 $25 \mu \mathrm{g} / \mathrm{kg} 48 \mathrm{~h}$ vs DXR 48 h, ** p=0.004; DXR + BLF501 $25 \mu \mathrm{g} / \mathrm{kg} 72 \mathrm{~h}$ vs DXR $72 \mathrm{~h},{ }^{*} p=0.0282$. Experiments were performed in triplicate. 


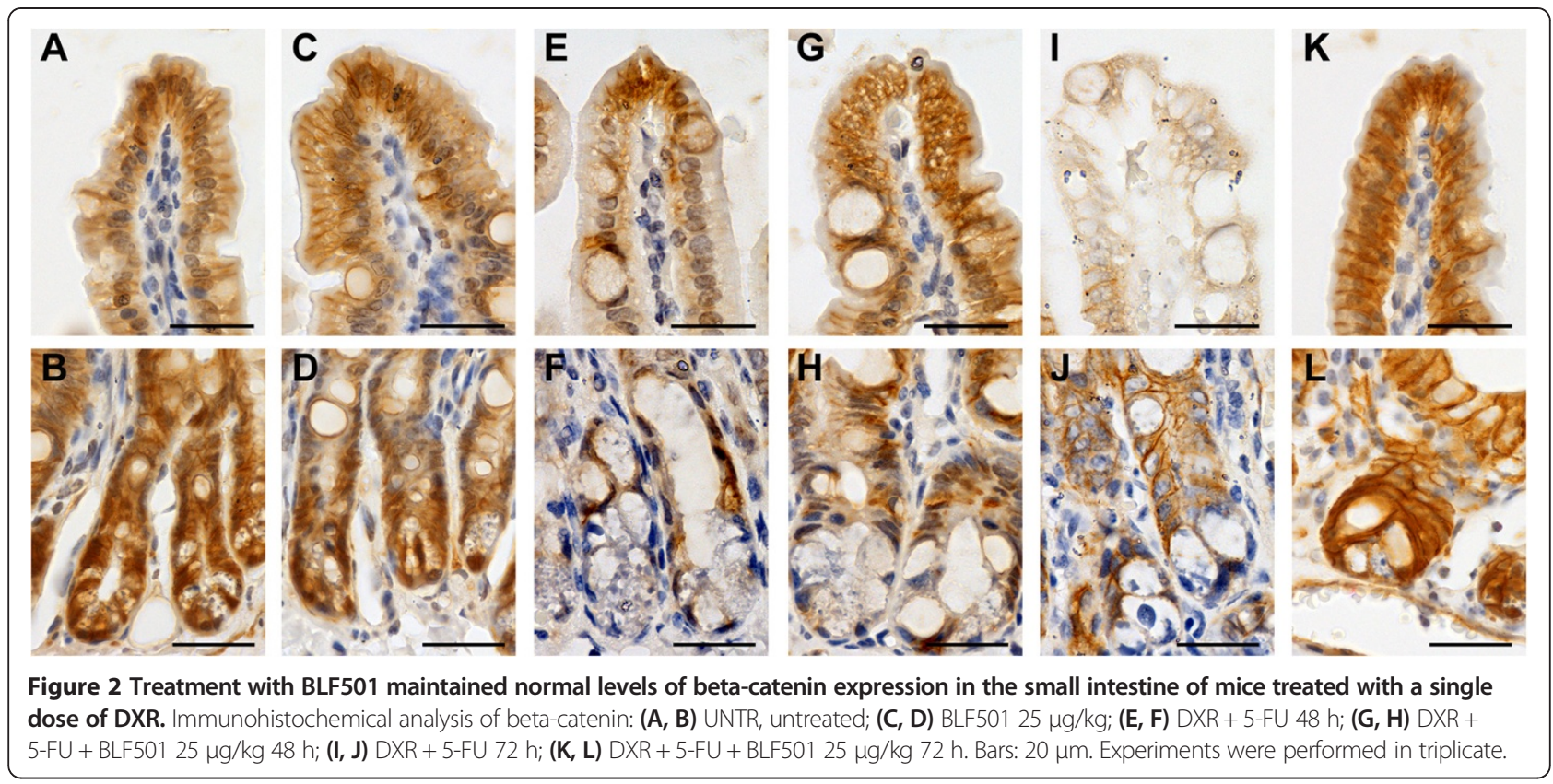

role in organizing membrane domains through their ability to interact with transmembrane proteins and cytoskeleton [34], and caspase-3, an apoptosis marker whose expression is increased by chemotherapeutic treatment [35]. Administration of DXR and 5-FU induced overexpression of ERM proteins and caspase-3, whereas co-administration of BLF501 $(25 \mu \mathrm{g} / \mathrm{kg})$ reduced caspase-3 expression and restored normal levels of expression of ERM proteins. Protein expression was normalized to that of GAPDH (Figure 5K-M).

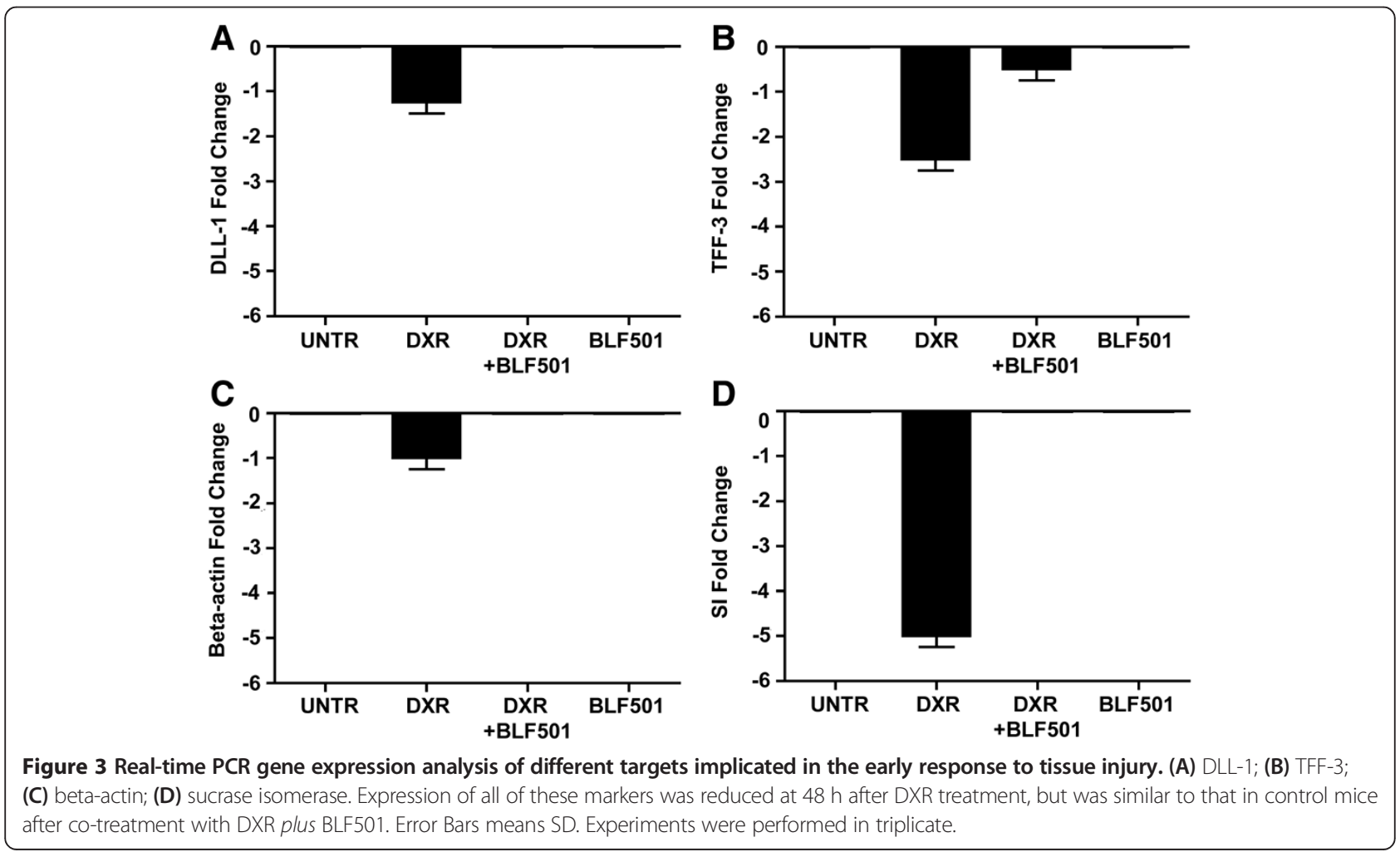




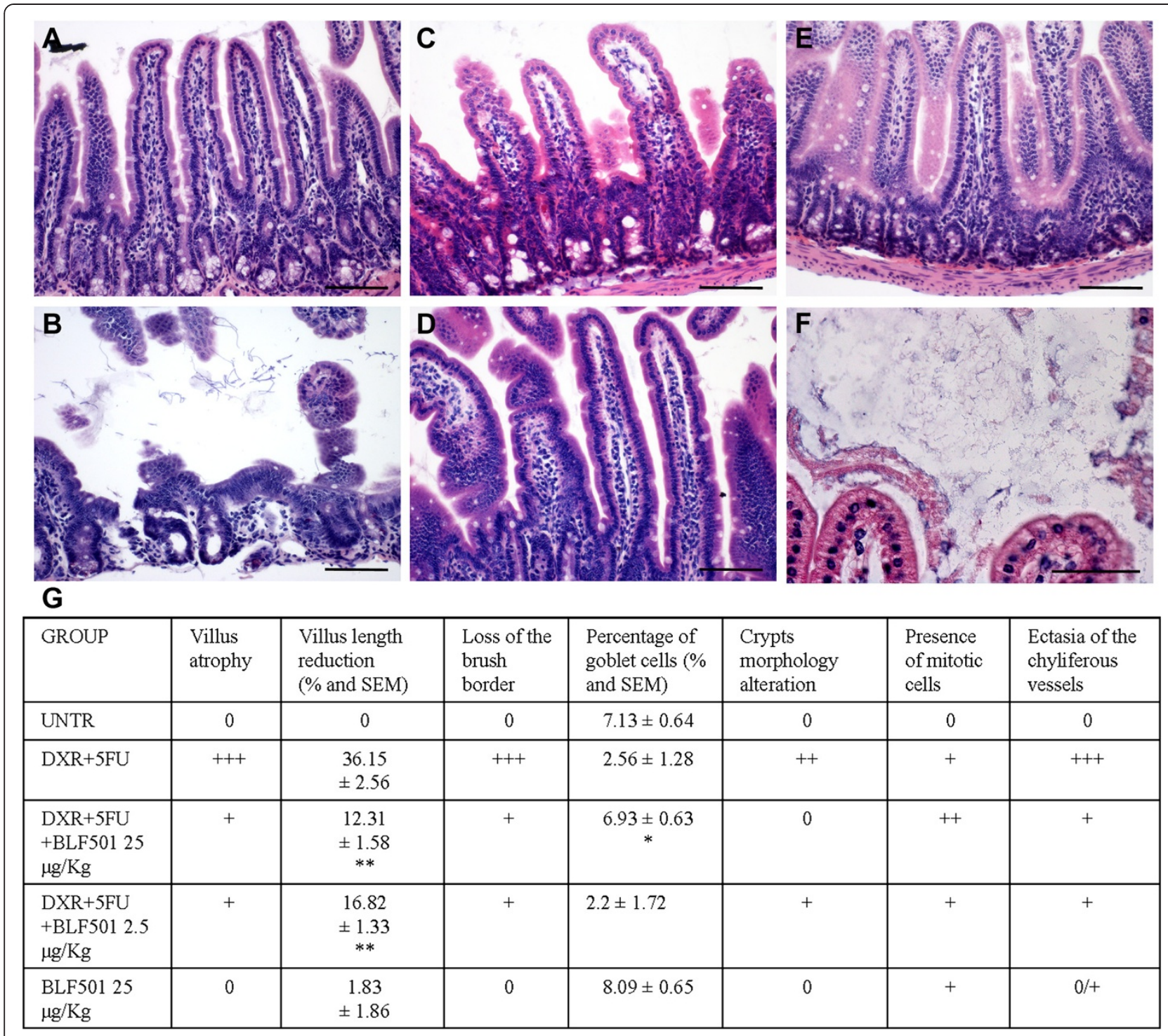

Figure 4 Dose-dependent BLF501-induced protection from injury to the mucosa of the small intestine in mice repeatedly injected with DXR and 5-FU. Histopathological detection of: (A) UNTR, untreated; (B) DXR + 5-FU; (C) DXR + 5-FU + BLF501 $2.5 \mu \mathrm{g} / \mathrm{kg}$; (D) DXR + 5-FU + BLF501 $25 \mu \mathrm{g} / \mathrm{kg}$; (E) BLF501 $25 \mu \mathrm{g} / \mathrm{kg}$; (F) DXR + 5-FU luminal bacterial content. (G) Summary of evaluated parameters. Statistical analysis: villus length,

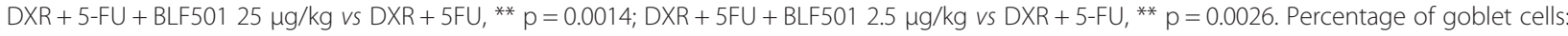

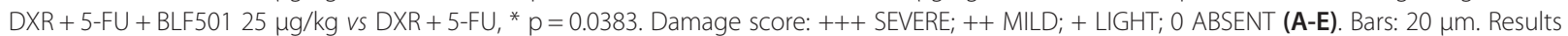
are from triplicate determinations.

\section{Oral administration of BLF501 does not interfere with the antitumor activity of DXR}

Overexpression of SGLT-1 is a survival strategy utilized by several tumor types, including EGFR-positive tumors [36]. Analysis of athymic (nude) mice injected subcutaneously with A431 cells, which strongly express both EGFR and SGLT-1 [37], showed that the tumor growth rate in mice co-treated with both DXR and BLF501 was similar to that in mice treated with DXR alone $(\mathrm{p}=0.1836)$ (Figure 6), indicating that oral administration of BLF501 does not interfere with DXR antitumor activity. Interestingly, while
DXR-treated mice showed an average reduction of body weight at the end of experiment, a slight increase in weight was observed in the group of mice treated with DXR and BLF501. No differences in tumor growth rate were observed between untreated mice and mice treated with BLF501 alone.

\section{Discussion}

The present data indicate that engagement of SGLT-1 by the synthetic D-glucose analog BLF501 promotes the protection of intestinal epithelial structures from injury 


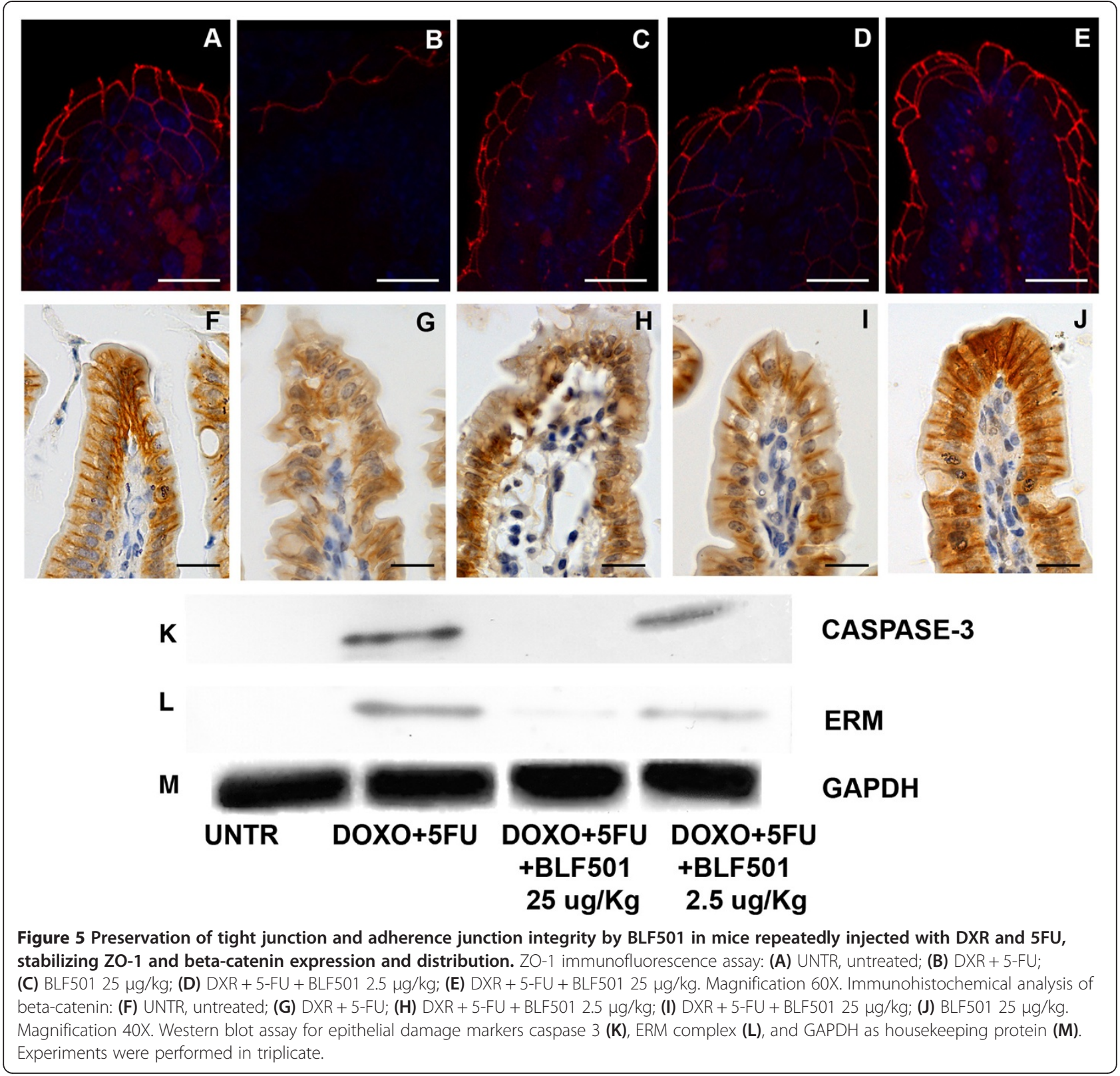

induced by DXR and 5-FU. This protective effect is independent of glucose metabolism, since BLF501 is a Cglycoside and, as such, does not enter the metabolic pathways of D-glucose [21]. The protective effect of the orally-administered SGLT-1 agonist 3-O-methyl-glucose (3-OMG), a non-metabolizable analog of D-glucose that does not enter glucose metabolic pathways, and of D-glucose has been previously reported in a model of LPS-induced injury to the intestinal mucosa [19]. It is noteworthy that the dose of BLF501 necessary to protect from DXR-induced injury was much lower than doses of D-glucose or 3-OMG shown to protect from LPS-induced injury $(25 \mu \mathrm{g} / \mathrm{kg}$ vs $2.5 \mathrm{~g} / \mathrm{kg})$. The ability of BLF501 to protect at low doses may reflect its high affinity for SGLT1 , a possibility supported by our previous in vitro finding that both D-glucose and BLF501 block LPS-induced release of IL-8, yet BLF501 is active at doses 106-fold lower than that of D-glucose [21].

Regarding the mechanism underlying the therapeutic effect of BLF501, oral administration indirectly protects the intestinal epithelium from chemotherapy-induced injury which was detectable at $48 \mathrm{~h}$ and was almost complete at $72 \mathrm{~h}$ after a single administration of DXR. Cellular proliferation assays performed on SGLT-1-/- mice demonstrate the pivotal role of SGLT-1 engagement by BLF501 to exert ligand biological activity; in fact, in the absence of SGLT-1, 

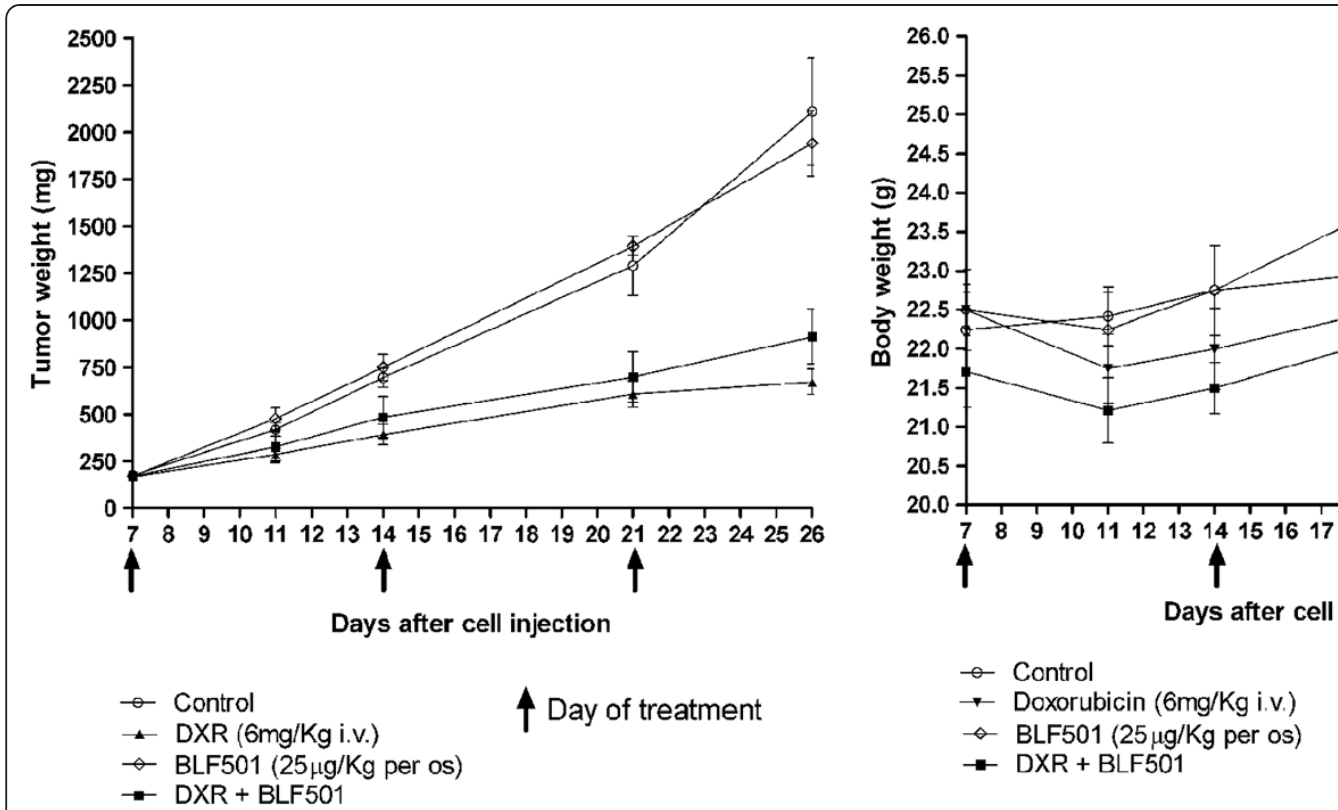

Figure 6 Tumor growth rate and weight in mice treated with chemotherapy alone or in conjunction with BLF501. Oral administration of BLF501 did not interfere with the antitumor activity of DXR. DXR-treated mice showed a reduction of body weight at the end of experiment, while a slight weight increase was observed in mice treated with DXR and BLF501. Error bars means SD Experiments were performed in triplicate.

no maintenance of proliferative processes was detected after BLF501 administration. Differences between the mean values of cell proliferation detected in wild-type and SGLT1-/- mice probably reflect existing physiological differences between the BALB/C and C57 strains or an altered metabolism in SGLT-1-/- vs wild-type mice.

Among the different modifications observed upon coadministration of BLF501 with chemotherapeutics, we found reduced expression of caspase- 3 in the intestines of co-treated mice compared to those treated with chemotherapeutics alone. This is likely due to a decrease in apoptotic events, consistent with recent reports that glucose administration reduces LPS-induced apoptotic events in enterocytes both in vitro and in vivo [16,38]. We also observed maintenance of the integrity of tight junctions in intestinal epithelia upon administration of BLF501 in mice treated with DXR and/or 5-FU, consistent with previous studies demonstrating that in the presence of heat- or chemical-induced sub-lethal stress conditions, activation of SGLT-1 preserves the integrity of tight junctions [16,18]. In particular, small intestine samples from mice treated with DXR and 5-FU showed altered expression and distribution of the junctional proteins ZO-1 and beta-catenin, whereas in mice co-treated with BLF501, ZO-1 and betacatenin were normally expressed and distributed. Moreover, the ERM complex, which has a physiological role in the remodeling of junctional mechanisms [17,39-43], overexpressed upon treatment of DXR and 5-FU treatment causing the opening of junctional systems; BLF501 co- treatment maintained ERM expression into normal levels in mice co-treated with BLF501.

In our mucositis models, BLF501 was found to preserve proliferation and integrity of junctional systems, as well as to reduce the expression of a marker of apoptosis. These beneficial effects on the overall integrity of the epithelium were confirmed histologically. These findings strongly favor the use of BLF501 as a therapeutic tool for the maintenance of the integrity of the intestinal epithelium in the setting of chemotherapy-induced injury. In fact, chemotherapeutics induce apoptotic cell death and inhibit proliferation in rapidly dividing epithelia such as the intestinal epithelium [44]. As a consequence, mucosal atrophy and a reduction of the absorption capacity of the intestine ensue, leading to further deterioration of the general condition of patients who are already heavily compromised.

The mechanism of interaction between SGLT-1 and its ligand BLF501 remains unknown. However based on several published findings $[42,45,46]$ and as schematized in Figure 7, we hypothesize that BLF501-induced SGLT-1 engagement initiates downstream cellular signaling involving MAPKPK-2 and AKT-2 with consequent GSK-3 phosphorylation. P-GSK-3 acts to inhibit p53-induced casapse-3 cleavage and to preserve the phosphorylated beta-catenin cytoplasmic pool, with positive effects on cellular proliferation mechanisms. At the same time, AKT-2 activation modulates tight junction expression via the ERM complex. Clarification of the cellular pathways involved in the protective activity of BLF501 awaits further in-depth analyses. 


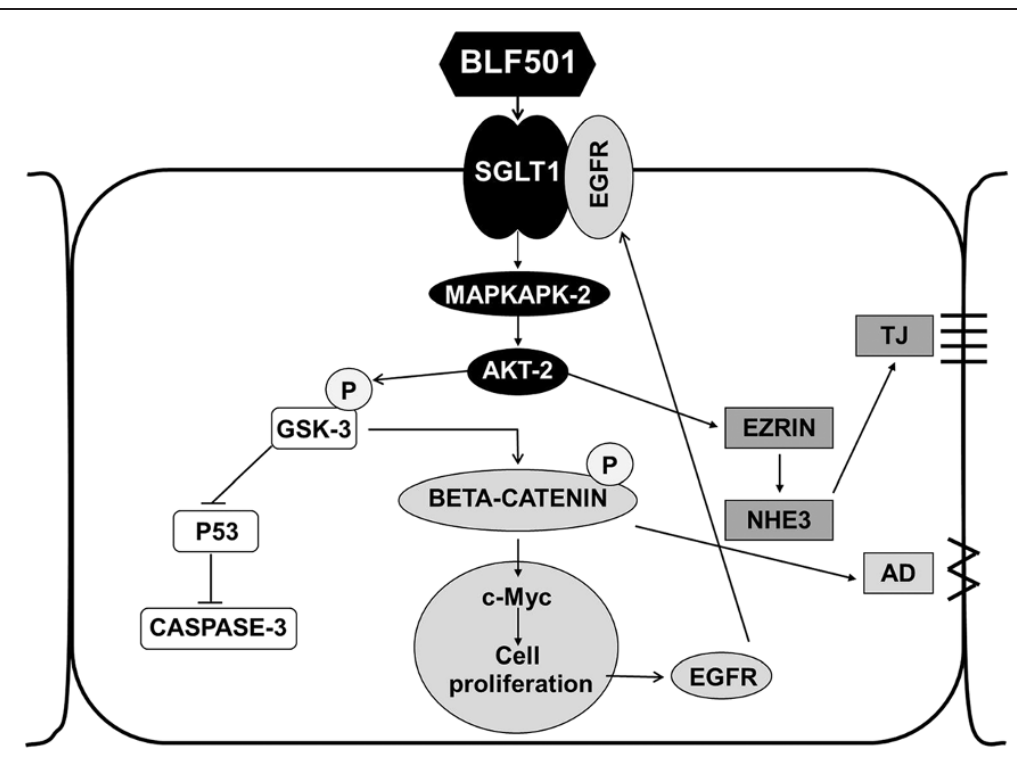

Figure 7 Hypothetical cellular pathways activated by BLF501-mediated SGLT-1 engagement. MAPKAPK-2/AKT-2 activation induces GSK-3 phosphorylation and consequent inhibition of p53-mediated caspase-3 cleavage. P-GSK-3 also preserves the cytoplasmic pool of beta-catenin involved in cellular proliferation mechanisms. Akt-2 is a key effector involved in tight junction management via ERM complex modulation.

In conclusion, our results show that oral administration of the non-metabolizable glucose analog BLF501 protects the intestinal mucosa from injuries induced by chemotherapeutic drugs. This suggests the prophylactic and/or therapeutic promise of BLF501 for the prevention or reduction of the severity of chemotherapy-induced mucositis. Moreover, orally administered BLF501 does not appear to interfere with the antitumor activity of the chemotherapeutics, with no difference in tumor growth between mice treated with DXR or DXR plus BLF501.

\section{Materials and methods}

\section{Cells and culture conditions}

A431 cells were purchased from ATCC (Rockville, MD) and authenticated using a panel of microsatellite markers (Istituto Nazionale Tumori, Milano, Italy). Cells were cultured in RPMI 1640 medium (Euroclone, Pero, Italy) supplemented with 10\% FBS (Euroclone), 1\% glutamine (Euroclone) and 1\% penicillin/streptomycin solutions (Euroclone). A431 cells in log phase were digested and cell suspensions were inoculated subcutaneously under sterile conditions into mice.

\section{C-glycoside BLF501}

The synthesis and a preliminary profiling of BLF501 have been described [21]. BLF501 resembles the structure (isosteric) of the natural O-glycoside, but cannot be metabolized (C-glycosides are unable to undergo glycolysis). BLF501 is water-soluble $(5 \mathrm{mM})$ and stable for several days at $25^{\circ} \mathrm{C}$ at pH 1-12 (stored in the dark).

\section{Mice and in vivo treatments}

Eight-week-old female BALB/c and nude SKH-1 mice were purchased from Charles River Italy (Calco, Italy). SGLT-1 ${ }^{-/-}$ mice on a C57BL/6 background have recently been described [17]. Mice were housed in specific aseptic conditions at constant temperature and humidity, with food and water given ad libitum. Mice were fed a specific normocaloric chow which does not contain glucose and galactose (Altromin C1000, Rieper, BZ, Italy). Experimental protocols were approved by the Ethics Committee for Animal Experimentation of the Istituto Nazionale Tumori (Milano, Italy), and conducted according to the guidelines of the United Kingdom Coordinating Committee on Cancer Research for animal welfare in experimental neoplasia (1998).

The effect of BLF501 on intestinal injury induced by a single injection of DXR (Pfizer; NY, USA) was evaluated in four groups of BALB/C mice: controls $(n=7)$; DXR $(\mathrm{n}=14)$; DXR plus BLF501 $(\mathrm{n}=14)$; and BLF501 $(\mathrm{n}=14)$. DXR $(20 \mathrm{mg} / \mathrm{kg}$ in saline, total volume $300 \mu \mathrm{l})$ was administered by i.p. injection. BLF501 $(25 \mu \mathrm{g} / \mathrm{kg}$ in saline, total volume $100 \mu \mathrm{l}$ ) was administered at the same time by gavage using a gastric tube. Control mice were treated i.p. with saline. One hour before sacrifice, bromodeoxyuridine (BrdU, Novocastra, Newcastle, UK) was injected i.p to determine cell proliferation. Control mice were sacrificed after $72 \mathrm{~h}$. Mice from the other groups were sacrificed at $48(\mathrm{n}=7)$ and at $72 \mathrm{~h}(\mathrm{n}=7)$ after treatment (Table 1$)$ 
[47]. SGLT-1 ${ }^{-/-}$mice were randomly divided into three groups: UNTR; DXR; and DXR + BLF501 $25 \mu \mathrm{g} / \mathrm{kg}$. ( $\mathrm{n}=7$ / group) (Table 1) and sacrificed after $72 \mathrm{~h}$.

The effect of BLF501 on intestinal injury induced by repeated injections of DXR and 5-FU (TEVA; Petah Tikva, Israel) was evaluated in six groups ( $\mathrm{n}=7$ /group): controls; DXR/5 + FU; DXR/5 + FU + BLF501 (0.25 $\mu \mathrm{g} / \mathrm{kg}) ; \mathrm{DXR}+5-$ FU + BLF501 (2.5 $\mu \mathrm{g} / \mathrm{kg}) ; \mathrm{DXR}+5-\mathrm{FU}+$ BLF501 $(25 \mu \mathrm{g} / \mathrm{kg})$; BLF501 $(25 \mu \mathrm{g} / \mathrm{kg})$. DXR (7 mg/kg) and 5-FU (100 ng/kg), dissolved in saline solution in a final volume of $300 \mu \mathrm{l}$, were administered i.p. once per week for 3 weeks. BLF501 (in saline, $100 \mu$ f final volume) was administered at the same time by gavage using a gastric tube. Mice were sacrificed on day 19 after starting treatment (Table 1).

The effect of BLF501 on the antitumor activity of DXR was tested in four groups ( $\mathrm{n}=8$ /group) of nude SKH-1 mice bearing SGLT-1-positive A431 mammary tumors that had reached a mean weight of $240 \mathrm{mg}$ : controls; DXR $(6 \mathrm{mg} / \mathrm{kg}$ in $200 \mu \mathrm{l}$ saline $)+$ BLF501 $(25 \mu \mathrm{g} / \mathrm{kg}$ in $100 \mu \mathrm{l} \mathrm{sa}-$ line); DXR alone; BLF501 alone. DXR was administered intravenously (i.v.) once per week for 3 weeks. BLF501 was administered at the same time by gavage using a gastric tube. Mice were sacrificed on day 26 of treatment (Table 1). Statistical significance was assessed using $X^{2}$ analysis.

\section{Processing of samples and histological evaluation}

Mice were sacrificed and jejunum samples were collected and fixed in $10 \%$ formalin with $2 \%$ sucrose in phosphate buffer for $4 \mathrm{~h}$ at $4^{\circ} \mathrm{C}$ and processed for paraffin embedding. Other jejunum samples were collected and preserved in liquid nitrogen for mRNA and protein extraction.

For histological examination, slides were stained with hematoxylin and eosin. Histological images were captured and digitized. Villus height was measured using Image Pro Plus 4 image analysis software (Media Cybernetics, Baltimore, MD). The degree of intestinal tissue injury was evaluated on a grading scale of : $+++=$ severe; $++=$ mild; + = light; 0 = absent.

\section{ZO-1 immunofluorescence}

Briefly, sample sections on slides were deparaffinized and hydrated for $1 \mathrm{~h}$ through a descending scale of alcohols. After a quick rinse with $0.1 \mathrm{M}$ Tris- $\mathrm{HCl}, \mathrm{pH} 7.4$, sections were incubated with proteinase $\mathrm{K}(20 \mathrm{~g} / \mathrm{ml})$ Tris-EDTA buffer, $\mathrm{pH} 8$, for $15 \mathrm{~min}$ at $37^{\circ} \mathrm{C}$, washed with Tris- $\mathrm{HCl}$ and permeabilized with $1 \%$ Triton $\mathrm{X}-100$ in Tris- $\mathrm{HCl}$ for $5 \mathrm{~min}$. Sections were treated with blocking solution for $1 \mathrm{~h}$ at room temperature and incubated overnight at $4^{\circ} \mathrm{C}$ with $20 \mu \mathrm{g} / \mathrm{ml}$ primary anti-mouse ZO-1 rabbit antibody ( $\alpha$-ZO-1, Invitrogen, Camarillo, CA). After washing, samples were incubated with secondary goat anti-rabbit antibody conjugated to tetramethyl-rhodamine isothiocyanate (TRITC; DyLight Jackson, West Baltimore Pike West Grove, PA, US) diluted 1:1000 in Tris- $\mathrm{HCl}$ for $45 \mathrm{~min}$ at room temperature. Sections were incubated with DAPI (1:10000 in Tris- $\mathrm{HCl}$ ) for $5 \mathrm{~min}$ at room temperature and washed 3 times with Tris- $\mathrm{HCl}$ and $0.01 \%$ Triton $\mathrm{X}-100$. Slides were mounted with Mowiol.

\section{Beta-catenin immunohistochemistry}

Sample sections on slides were deparaffinized and hydrated for $1 \mathrm{~h}$ through a descending scale of alcohols. Antigen retrieval was performed using two antigen unmasking steps of $5 \mathrm{~min}$ in a microwave oven with citrate buffer, $\mathrm{pH} 6$ $(0.005 \mathrm{M})$. Sections were cooled and then washed with $0.1 \mathrm{M}$ Tris- $\mathrm{HCl}, \mathrm{pH} 7.4,+0.025 \%$ Triton X-100. Samples were treated with a peroxidase inhibition solution of $3 \%$ $\mathrm{H}_{2} \mathrm{O}_{2}$ in $0.1 \mathrm{M}$ Tris- $\mathrm{HCl}, \mathrm{pH}$ 7.4, for $20 \mathrm{~min}$ and nonspecific sites were blocked with HHG solution (1 mM Hepes, $2 \%$ goat serum, $1 \mathrm{X}$ HBSS, $0.5 \%$ Triton $\mathrm{X}-100$ ) in Tris- $\mathrm{HCl}$ for $1 \mathrm{~h}$ at room temperature. Sections were then incubated for $2 \mathrm{~h}$ at room temperature with a primary anti-betacatenin rabbit antibody diluted 1:500 (Abcam, Cambridge, UK), washed, and incubated for $45 \mathrm{~min}$ at room temperature with a biotinylated secondary goat anti-rabbit antibody diluted 1:1000. Finally, sections were incubated with $\mathrm{ABC}$-kit and DAB (Vector, Burlingame, VT, US), counterstained with hematoxylin, dehydrated through an ascending scale of alcohols and xylene, and mounted with coverslips using Entellan (Merck, Darmstadt, Germany).

\section{BrdU immunofluorescence}

Sample sections on slides were deparaffinized and hydrated for $1 \mathrm{~h}$ through a descending scale of alcohols, rinsed in PBS and incubated at room temperature with $2 \mathrm{~N} \mathrm{HCl}$ for $30 \mathrm{~min}$ and with $\mathrm{Na}_{2} \mathrm{~B}_{4} \mathrm{O}_{7}$ for $10 \mathrm{~min}$. Sections were incubated with $\mathrm{PBS} / 3 \% \mathrm{BSA}$ for $20 \mathrm{~min}$ at room temperature and with proteinase $\mathrm{K}(20 \mathrm{~g} / \mathrm{ml})$ TrisEDTA buffer, $\mathrm{pH} \mathrm{8,} \mathrm{for} 15 \mathrm{~min}$ at $37^{\circ} \mathrm{C}$. After washing, slides were incubated for $1 \mathrm{~h}$ at room temperature with a primary anti-BrdU mouse antibody (Novocastra) diluted 1:200 in PBS/3\% BSA, washed, and incubated with secondary goat anti-mouse DyLight 488 antibody (Jackson) diluted 1:500 in PBS/BSA 3\%. Sections were washed, incubated for $5 \mathrm{~min}$ at room temperature with DAPI diluted 1:2500 in PBS, and mounted with Mowiol.

All samples were observed and photographed with a microscope Nikon Eclipse 80 with a digital camera Nikon DS-L1.

\section{Real-time polymerase-chain reaction (PCR)}

RNA was extracted from frozen jejunum samples using TRI-reagent (Sigma-Aldrich, St. Louis, MO, US) and transcribed with a reverse transcription kit (Applied Biosystems, Foster City, CA, US). Real-time PCR experiments were performed according to the manufacturer's instructions using a 7900HT Fast Real-Time PCR System (Applied Biosystems). Primers for SI, TFF3, DLL1, 
beta-actin and the housekeeping gene $18 \mathrm{~S}$ were purchased from Applied Biosystems.

\section{Western blot analysis}

Expression of caspase- 3 and ERM complex was assessed on total phosphorylated protein extracted from small intestine samples of mice using our TNTG buffer $(40 \mathrm{mM}$ Tris, pH 7.5, $100 \mathrm{mM} \mathrm{NaCl}, 10 \%$ glycerol, $1 \%$ Triton X100 , proteases inhibitors). Protein extracts were quantified using the BCA method (BCA Protein Assay Kit, Pierce, Rockford, IL, US). Proteins ( $30 \mu \mathrm{g})$ were fractionated on a polyacrylamide gel (BIO-RAD Labs, Hercules, CA) and electroblotted onto nitrocellulose filters (American Biosciences, Buckinghamshire, UK). Filters were incubated for $1 \mathrm{~h}$ in TBS containing 5\% milk powder to block nonspecific binding sites, followed by anti-caspase- 3 antibody $(1 \mu \mathrm{g} / \mathrm{ml}$; Abcam), anti-GAPDH antibody (1:1000; Abcam) and anti-ERM antibody (1:1000; Cell Signaling Technologies, Danvers, MA, US), and finally with appropriate antigoat and anti-rabbit secondary anti-peroxide antibody (Vector Laboratories). Bands were visualized using $\mathrm{ECL}^{\mathrm{m}}$ Western Blotting Detection Reagents and plates by autoradiography (American Biosciences).

\section{Statistical analyses}

Student's t-test (paired two-tailed), $x^{2}$ analysis and GraphPad Prism software (GraphPad Prism Software Inc., San Diego, CA) were used for comparisons between groups. Differences were considered significant at $\mathrm{p}<0.05$.

\section{Competing interests}

The authors declare that they have no competing interests.

\section{Authors' contributions}

DC and CR made initial observations, designed the main experiments, analyzed the data and wrote the manuscript; BLF and GD designed and performed the synthesis of BLF501 molecule; DC, CS and MS performed all of the studies involving animal models, including histological and immunohistochemical analyses, biochemical assays and molecular biology experiments, and contributed to manuscript preparation; DO performed all anatomopathological analysis; FM, AB, FN, and ET supervised the project and data interpretation and contributed to manuscript preparation; HK make the SGLT-1 KO mice available and contributed to data interpretation; CR designed the experimental approach, coordinated the project and wrote the manuscript. All authors have read and approved the final manuscript.

\section{Author details}

'Department of Pharmacology and Biomolecular Sciences, Università degli Studi di Milano, Via Trentacoste 2, 20133 Milan, Italy. ${ }^{2}$ Humanitas Clinical and Research Center, Via Manzoni 56, 20089 Rozzano, Milan, Italy. ${ }^{3}$ Department of Biotechnology and Bioscience \& CINMPIS, Università degli Studi di Milano-Bicocca, Piazza della Scienza 2, 20126 Milan, Italy. ${ }^{4}$ Dipartimento di Scienze Biomediche per la Salute, Università degli Studi di Milano, Via Mangiagalli 31, 20133 Milan, Italy. Istituto Nazionale per lo Studio e la Cura dei Tumori, Via Venezian, 1, 20133 Milano, Italy. ${ }^{6}$ Regina Elena National Cancer Institute, Via E. Chianesi 53, 00144 Rome, Italy. ${ }^{7}$ BiEssseA, Via A. D'Aosta 7, 20129 Milan, Italy. ${ }^{8}$ Department of Molecular Plant Physiology and Biophysics, Julius-von-Sachs-Institute, University of Würzburg, 97082 Würzburg, Germany.

Received: 17 July 2013 Accepted: 27 January 2014

Published: 5 February 2014
References

1. Keefe DM: Intestinal mucositis: mechanisms and management. Curr Opin Oncol 2007, 19:323-327.

2. Carvalho C, Santos RX, Cardoso S, Correia S, Oliveira PJ, et al: Doxorubicin the good, the bad and the ugly effect. Curr Med Chem 2009, 16:3267-3285.

3. Honda M, Miura A, Izumi Y, Kato T, Ryotokuji T, et al: Doxorubicin, cisplatin, and fluorouracil combination therapy for metastatic esophageal squamous cell carcinoma. Dis Esophagus 2010, 23:641-645.

4. Sonis ST: The pathobiology of mucositis. Nat Rev Cancer 2004, 4:277-284.

5. Sonis ST: A biological approach to mucositis. J Support Oncol 2004, 2:21-32.

6. Scardina GA, Pisano T, Messina P, Oral mucositis: Review of literature. N Y State Dent 2010, 76:34-38.

7. Sonis ST: Regimen-related gastrointestinal toxicities in cancer patients. Curr Opin Support Palliat Care 2010, 4:26-30.

8. Sonis ST: Pathobiology of mucositis. Semin Oncol Nurs 2004, 20:11-15.

9. Spielberger R, Stiff P, Bensinger W, Gentile T, Weisdorf D, et al: Palifermin for oral mucositis after intensive therapy for hematologic cancers. N Engl J Med 2004, 351:2590-2598.

10. Rubenstein EB, Peterson DE, Schubert M, Keefe D, McGuire D, et al: Clinical practice guidelines for the prevention and treatment of cancer therapy-induced oral and gastrointestinal mucositis. Cancer 2004, 100:2026-2046.

11. Keefe DM, Schubert MM, Elting LS, Sonis ST, Epstein JB, et al: Updated clinical practice guidelines for the prevention and treatment of mucositis. Cancer 2007, 109:820-831.

12. Gibson RJ, Keefe DM, Lalla RV, Bateman E, Blijlevens N, et al: Systematic review of agents for the management of gastrointestinal mucositis in cancer patients. Support Care Cancer 2013, 21:313-326.

13. Bhatt V, Vendrell N, Nau K, Crumb D, Roy V: Implementation of a standardized protocol for prevention and management of oral mucositis in patients undergoing hematopoietic cell transplantation. J Oncol Pharm Pract 2010, 16:195-204.

14. Wu JC, Beale KK, Ma JD: Evaluation of current and upcoming therapies in oral mucositis prevention. Future Oncol 2010, 6:1751-1770.

15. Banerjee SK, McGaffin KR, Pastor-Soler NM, Ahmad F: SGLT1 is a novel cardiac glucose transporter that is perturbed in disease states. Cardiovasc Res 2009, 84:111-118.

16. Ikari A, Nagatani $Y$, Tsukimoto M, Harada H, Miwa M: Sodium-dependent glucose transporter reduces peroxynitrite and cell injury caused by cisplatin in renal tubular epithelial cells. Biochim Biophys Acta 2005, 1717:109-117.

17. Gorboulev V, Schürmann A, Vallon V, Kipp H, Jaschke A, et al: Na(+)-Dglucose cotransporter SGLT1 is pivotal for intestinal glucose absorption and glucose-dependent incretin secretion. Diabetes 2012, 61:187-196.

18. Ikari A, Nakano M, Suketa Y, Harada H, Takagi K: Reorganization of ZO-1 by sodium-dependent glucose transporter activation after heat stress in LLC-PK1 cells. J Cell Physiol 2005, 203:471-478.

19. Palazzo M, Gariboldi S, Zanobbio L, Selleri S, Dusio GF, et al: Sodiumdependent glucose transporter-1 as a novel immunological player in the intestinal mucosa. J Immunol 181:3126-3136 Erratum in. J Immunol 2008, 181:7428.

20. Yu LC, Flynn AN, Turner JR, Buret AG: SGLT-1-mediated glucose uptake protects intestinal epithelial cells against LPS-induced apoptosis and barrier defects: a novel cellular rescue mechanism? FASEB J 2005, 19:1822-1823.

21. La Ferla B, Spinosa V, D'Orazio G, Palazzo M, Balsari A, et al: Dansyl C-glucoside as a novel agent against endotoxic shock. Chem Med Chem 2010, 5:1677-1680.

22. Dekaney CM, Gulati AS, Garrison AP, Helmrath MA, Henning SJ: Regeneration of intestinal stem/progenitor cells following doxorubicin treatment of mice. Am J Physiol Gastrointest Liver Physiol 2009, 297:G461-70.

23. Liu L, Rao JN, Zou T, Xiao L, Smith A, Zhuang R, et al: Activation of Wnt3a signaling stimulates intestinal epithelial repair by promoting c-Myc-regulated gene expression. Am J Physiol Cell Physiol 2012, 302:C277-C285.

24. Kühl SJ, Kühl M: On the role of Wnt/ß-catenin signaling in stem cells. Biochim Biophys Acta 2013, 1830:2297-2306.

25. De Koning BA, Lindenbergh-Kortleve DJ, Pieters R, Büller HA, Renes IB: Alterations in epithelial and mesenchymal intestinal gene expression during doxorubicin-induced mucositis in mice. Dig Dis Sci 2007, 52:1814-1825.

26. Pellegrinet L, Rodilla V, Liu Z, Chen S, Koch U, et al: Dll1- and dll4-mediated notch signaling are required for homeostasis of intestinal stem cells. Gastroenterology 2012, 140:1230-1240. 
27. Beck PL, Wong JF, Li Y, Swaminathan S, Xavier RJ, et al: Chemotherapy- and radiotherapy-induced intestinal damage is regulated by intestinal trefoil factor. Gastroenterology 2004, 126:796-808.

28. Bruininx EM, Koninkx JF, Binnendijk GP, Zandstra T, Heetkamp MJ, et al: Effects of prefermented cereals or the end products of fermentation on growth and metabolism of enterocyte-like Caco- 2 cells and on intestinal health of restrictedly fed weanling pigs. Animal 2010, 4:40-51.

29. Kaczmarek A, Brinkman BM, Heyndrickx L, Vandenabeele P, Krysko DV: Severity of doxorubicin-induced small intestinal mucositis is regulated by the TLR-2 and TLR-9 pathways. J Pathol 2012, 226:598-608.

30. Han X, Wu Z, Di J, Pan Y, Zhang H, et al: CXCL9 attenuated chemotherapyinduced intestinal mucositis by inhibiting proliferation and reducing apoptosis. Biomed Pharmacother 2011, 65:547-54.

31. Huang TY, Chu HC, Lin YL, Ho WH, Hou HS, et al: Minocycline attenuates 5-fluorouracil-induced small intestinal mucositis in mouse model. Biochem Biophys Res Commun 2009, 389:634-639.

32. Salama NN, Eddington ND, Fasano A: Tight junction modulation and its relationship to drug delivery. Adv Drug Deliv Rev 2006, 58:15-28.

33. Scardina GA, Pisano T, Messina P: Oral mucositis. Review of literature. N Y State Dent J 2010, 76:34-38.

34. Fanning AS, Van Itallie CM, Anderson JM: Zonula occludens-1 and -2 regulate apical cell structure and the zonula adherens cytoskeleton in polarized epithelia. Mol Biol Cell 2012, 23:577-590.

35. Tabibzadeh S, Kong QF, Kapur S, Satyaswaroop PG, Aktories K: Tumour necrosis factor-alpha-mediated dyscohesion of epithelial cells is associated with disordered expression of cadherin/beta-catenin and disassembly of actin filaments. Hum Reprod 1995, 10:994-1004.

36. Chen YL, Loh SH, Chen JJ, Tsai CS: Urotensin II prevents cardiomyocyte apoptosis induced by doxorubicin via Akt and ERK. Eur J Pharmacol 2012, 680:88-94.

37. Fehon RG, McClatchey Al, Bretscher A: Organizing the cell cortex: the role of ERM proteins. Nat Rev Mol Cell Biol 11:276-287. Review. Erratum in. Nat Rev Mol Cell Biol 2010, 11:674.

38. Gatenby RA, Gillies RJ: Why do cancers have high aerobic glycolysis? Nat Rev Cancer 2004, 4:891-899.

39. Engelman JA, Cantley LC: A sweet new role for EGFR in cancer. Cancer Cell 2008, 13:375-376.

40. Turner JR, Rill BK, Carlson SL, Carnes D, Kerner R, Mrsny RJ, et al: Physiological regulation of epithelial tight junctions is associated with myosin light-chain phosphorylation. Am J Physiol 1997, 273:C1378-1385.

41. Lin R, Murtazina R, Cha B, Chakraborty M, Sarker R, Chen TE, et al: D-glucose acts via sodium/glucose cotransporter 1 to increase NHE3 in mouse jejunal brush border by a $\mathrm{Na}+/ \mathrm{H}+$ exchange regulatory factor 2-dependent process. Gastroenterology 2011, 140:560-571.

42. Fouassier L, Duan CY, Feranchak AP, Yun CH, Sutherland E, et al: Ezrin-radixin-moesin-binding phosphoprotein is expressed at the apical membrane of rat liver epithelia. Hepatology 2001, 33:166-176.

43. Hu Z, Wang Y, Graham WV, Su L, Musch MW: MAPKAPK-2 is a critical signaling intermediate in NHE3 activation following $\mathrm{Na}+$-glucose cotransport. J Biol Chem 2006, 281:24247-53.

44. Wu KL, Khan S, Lakhe-Reddy S, Jarad G, Mukherjee A, et al: The NHE1 $\mathrm{Na}+\mathrm{H}+$ exchanger recruits ezrin/radixin/moesin proteins to regulate Akt-dependent cell survival. J Biol Chem 2004, 279:26280-26286.

45. Keefe DM, Brealey J, Goland GJ, Cummins AG: Chemotherapy for cancer causes apoptosis that precedes hypoplasia in crypts of the small intestine in humans. Gut 2000, 47:632-637.

46. Ngok-Ngam P, Watcharasit P, Thiantanawat A, Satayavivad J: Pharmacological inhibition of GSK3 attenuates DNA damage-induced apoptosis via reduction of p53 mitochondrial translocation and Bax oligomerization in neuroblastoma SH-SY5Y cells. Cell Mol Biol Lett 2013, 18:58-74.

47. Freyberg Z, Ferrando SJ, Javitch JA: Roles of the Akt/GSK-3 and Wnt signaling pathways in schizophrenia and antipsychotic drug action. Am J Psychiatry 2010, 167:388-96.

\section{doi:10.1186/1476-4598-13-23}

Cite this article as: Cardani et al: Sodium glucose cotransporter 1 ligand BLF501 as a novel tool for management of gastrointestinal mucositis. Molecular Cancer 2014 13:23.

\section{Submit your next manuscript to BioMed Central and take full advantage of:}

- Convenient online submission

- Thorough peer review

- No space constraints or color figure charges

- Immediate publication on acceptance

- Inclusion in PubMed, CAS, Scopus and Google Scholar

- Research which is freely available for redistribution 